\title{
Effects of 6-Week Resistance Elastic Band Exercise on Functional Performances of 8-9 Year-Old Children
}

\author{
İlbilge Özsu \\ Correspondence: İlbilge Özsu, Faculty of Sports Sciences, Uşak University, Uşak, Turkey.
}

Received: December 4, 2018

doi:10.11114/jets.v6i12a.3887

\author{
Accepted: December 13, $2018 \quad$ Online Published: December 17, 2018 \\ URL: https://doi.org/10.11114/jets.v6i12a.3887
}

\begin{abstract}
The purpose of this study was to investigate the effects of 6-week exercises performed by elastic resistance band on functional performance (balance, agility, hand grip strength and flexibility) in children aged 8-9 years. So, 102 students participated in this study according to pre-test and post-test design. Participants were divided into two groups: experimental group ( $\mathrm{n}=50$, height: $134.0 \pm 6.3 \mathrm{~cm}$, mass: $30.9 \pm 7.9 \mathrm{~kg}$, age: $8.6 \pm 0.5$ years) and control group ( $\mathrm{n}=52$, height: $135.0 \pm 6.2 \mathrm{~cm}$, mass: $32.4 \pm 5.9 \mathrm{~kg}$, age: $8.6 \pm 0.6$ years). The experimental group performed exercises using elastic resistance bands of lightness grade at the same time of day (45 minutes/day, 3 days/week), and the control group did not participate in any physical activity. Balance was measured by Flamingo Test, agility by Ilinois, flexibility by sit and reach box and strength was measured by hand-grip dynamometer. It was determined that 6-week exercises performed by elastic resistance band increased significantly the hand grip strength; however there was no statistically significant effect on balance, agility and flexibility abilities.

The inclusion of elastic resistance band exercises in the context of school activity programs can improve children's strengths. For this reason, exercises performed by elastic resistance bands for more than 6 weeks can be added to activity programs in school as an economical, fun and reliable way to improve the hand-grip performance of children.
\end{abstract}

Keywords: elastic resistance band, exercise, children, flexibility, balance, agility

\section{Introduction}

Physical education begins at early ages. The games at early ages and in primary school activities constitute of the most important starting steps for healthy growth of children. However, the technology, which is the necessity of the era we live in, put the children away from the natural play environment and accordingly it blocks the many bio-motor abilities that should be acquired by age, or inhibit healthy development. The advancement of technology and the reduction of space and time allocated to children in city life cause children to stay away from many games, which provide a development of bio-motor abilities and have a healthy body structure by tree-climbing, running, jumping, leaping, and so on. For this reason, the child's healthy body structure should be supported by special training programs by organizing various movement trainings (Özer, 2000) and so then one of the most effective ways is resistance training.

Properly planned resistance training in healthy children is a safe and effective way to improve children's physical performance (Behringer et al., 2011; Faigenbaum et al., 2010; Faigenbaum et al., 2007; Behm, et al., 2008). Resistance training designed qualitatively and carried out under a professional is an effective strategy for improving physical and psychosocial characteristics of children as well as reducing sports-related injury rates (Faigenbaum and Myer, 2009). The regular resistance training increases muscle strength of children and adolescents (Faigenbaum et al., 1993), motor skills such as jumping (Lesinski et al., 2016) and increases bone development, facilitating weight control (Faigenbaum, 2007; Myer and Wall, 2006), improves body composition (Faigenbaum et al., 2009; Faigenbaum et al., 1993). Besides the known positive effects of resistance exercises on children's health and motor performance is to strengthen the distal and proximal parts of the long bones (such as ulna, femur and tibia (Caine et al., 2006), humerus (Osbahr et al., 2002; Reagan et al., 2002), articular cartilage and epiphysis. Growth cartilages in children are in ossification process and weaker than connective attached tissue. This causes growth cartilage to be more easily damaged by repeated traumas (Faigenbaum et al., 2009). Damaging of growth cartilage may result serious pain and growth disorders during the training period (Caine et al., 2006). These injuries are due to the lack of professionalism in the sports branch (Difiori et al., 2006), the wrong applied skill and overloading (Connolly et al., 2001). Studies on resistance training in children reported no cartilage injury at all (Falk and Eliakim, 2003; Malina, 2006) and numerous studies have shown that 
resistance training for can be safe and effective with appropriate surveillance and precautions (Falk and Eliakim, 2003; Canli, 2017; Faigenbaum and Myer, 2010).

Elastic resistance bands are one of the most widely used equipment for resistance training. These bands can be used by individuals of all ages are produced in different hardness (light-medium-high hardness) in accordance with individual's fitness level, and hardness of the band varies according to the colors. The hardness of the bands, which are easily used at home, in open area or in a sport center, can be increased over time according to the progressive overload principle in training and can be effectively applied in single or multi-joint movements.

Studies on elastic resistance band exercises performed regularly in children (11-13 years) developed muscular strength, flexibility, balance and some motoric features (shuttle-push-pull) (Yolcu, 2010; Selçuk, 2013), muscular stamina, vertical jump and the repetition numbers of 1 set in squat exercises (Şahin et al., 2016). When the literature is reviewed, there are studies about the elastic resistance bands in adolescents, but there is no research on children before puberty.

The aim of this study is to investigate the effects of 6-week elastic resistance band exercises on flexibility, balance, agility and strength abilities of 8-9 age group children. It is thought that elastic resistance band trainings performed regularly for 3 days of a week, for 6 weeks would reveal a statistically significant improvement on flexibility, balance, agility and strength abilities of 8-9 years old children.

\section{Methods}

\subsection{Participants}

A total of 102 students participated in this research with the permission of their parents and on a voluntary basis. Participants were randomly divided into two groups: experimental group $(\mathrm{n}=50$, height: $134.0 \pm 6.3 \mathrm{~cm}$, mass: $30.9 \pm 7.9$ $\mathrm{kg}$, age: $8.6 \pm 0.5$ year) and control group $(\mathrm{n}=52$, height: $135.0 \pm 6.2 \mathrm{~cm}$, mass: $32.4 \pm 5.9 \mathrm{~kg}$, age: $8.6 \pm 0.6$ year). Experimental group performed exercise for 45 minutes in the same hours of the day (3 days a week) using elastic resistance band with a slight degree of hardness (yellow colored), the control group did not participate in any physical activity. Experimental group performed according to the circular training design $(2 \times 15)$ is applied as follows; biceps curl, reverse flies, hip adduction, hip extension, Triceps extension, lateral rise, front rise, chest press, lateral pull down, squat. The study was approved by Uşak University Local Ethics Committee (approval number 2018-28).

\subsection{Collecting Data}

The data collection process took place at the beginning of the 6-week training period and at the end of the end.

Hand-Grip Strength: Hand-grip force was measured using digital hand dynamometer (Deyard EH101, United Kingdom). The participants held the dynamometer in an upright position, shoulder joint was neutralized in rotation, adducted with trunk, and held elbow in full extension (Saha, 2014). In this position, 3 measurements were taken at 20 second intervals and the best measured value was recorded in $\mathrm{kg}$.

Filamingo Test: The participants were asked to stand on a hard flat material of $5 \mathrm{~cm}$ height, $3 \mathrm{~cm}$ wide, $120 \mathrm{~cm}$ long, without any support for 1 minute on one foot. The times of children's imbalance was recorded during 1 minute.

Ilinois Agility Run Test: The test was established (10 m×5 times), and hand stopwatch (Casio HS-80TW-1JH, Japanese) was used to measure the course time.

Sit and Reach Box Test: The participants sat down on the floor with the knee full extension in front of a box with a height of $32 \mathrm{~cm}$ and a length of $35 \mathrm{~cm}$. After some practices they reached out as far as possible to the stand and hold that position without any jerky movement for two seconds. The point at which the fingertips reached were measured in $\mathrm{cm}$ and the best value of the 3 trials was recorded.

\subsection{Statistical Analysis}

Performance changes from pre to post-test were compared between groups using Mann-Whitney U test and descriptive statistics were reported as median (25/75 percentiles) by SPSS V23.0 (IBM) software at level of $p \leq 0.05$. Normality of residuals was checked by histograms and Shapiro-Wilk test. All performance chances were recorded as absolute changes since the changes in performance score "zero (0) (especially valid for flexibility and balance scores) cannot be identified as a relative or percent value. 


\section{Results}

Table 1. Statistical comparison of demographic characteristics between study groups

\begin{tabular}{llrccc}
\hline & Group & Median $(25 / 75$ percentiles $)$ & $\mathrm{Z}$ & $\mathrm{p}$ & $\mathrm{ES}$ \\
\hline \multirow{2}{*}{ Height $(\mathrm{cm})$} & Control & $1.34(1.29 / 1.37)$ & -0.616 & 0.538 & \multirow{2}{*}{0.06} \\
& Experiment & $1.33(1.29 / 1.37)$ & & & \\
\multirow{2}{*}{ Mass $(\mathrm{kg})$} & Control & $31.0(28.0 / 35.0)$ & -2.109 & $0.035^{*}$ & 0.21 \\
& Experiment & $28.0(25.0 / 34.3)$ & & & \\
\multirow{2}{*}{ Age (year) } & Control & $8.0(8.0 / 9.0)$ & -0.875 & 0.382 & 0.09 \\
\cline { 2 - 5 } & Experiment & $9.0(8.0 / 9.0)$ & & &
\end{tabular}

ES: Effect size (r) for Mann Whitney U Test; $r=0.1$ (small effect size). $r=0.3$ (medium effect size). $r=0.5$ (large effect size). ${ }^{*} \mathrm{p}<0.05$

As Table 1 shows, there was no difference between both groups in height and age ( $\mathrm{p}=0.538, \mathrm{p}=0.382$, respectively). However, there was significant difference between both groups in body mass $(\mathrm{p}=0.035)$. According to this result, it can be said that the height and ages of participants were similar but body masses differ between the groups.

Table 2. Statistical comparison of performance changes in dependent variables between study groups

\begin{tabular}{|c|c|c|c|c|c|c|c|}
\hline & Group & $\begin{array}{l}\text { Test } \\
\text { Time }\end{array}$ & Test Score & Absolute Change & Z & $\mathrm{p}$ & ES \\
\hline \multirow{4}{*}{ Balance (FC) } & \multirow{2}{*}{ Control } & Pre & $2.0(1.0 / 6.0)$ & \multirow{2}{*}{$-1.0(-2.0 / 1.0)$} & \multirow{4}{*}{-0.450} & \multirow{4}{*}{0.653} & \multirow{4}{*}{0.04} \\
\hline & & Post & $1.0(0.0 / 5.0)$ & & & & \\
\hline & \multirow{2}{*}{ Experiment } & Pre & $2.0(1.0 / 4.0)$ & \multirow{2}{*}{$0.0(-1.0 / 1.0)$} & & & \\
\hline & & Post & $1.5(0.0 / 3.0)$ & & & & \\
\hline \multirow{4}{*}{ Agility (s) } & \multirow{2}{*}{ Control } & Pre & $22.4(21.0 / 24.1)$ & \multirow{2}{*}{$-1.0(-1.7 / 0.4)$} & \multirow{4}{*}{-0.377} & \multirow{4}{*}{0.706} & \multirow{4}{*}{0.04} \\
\hline & & Post & $21.1(21.0 / 24.0)$ & & & & \\
\hline & \multirow{2}{*}{ Experiment } & Pre & $22.7(21.7 / 23.8)$ & \multirow{2}{*}{$-0.8(-1.4 / 0.0)$} & & & \\
\hline & & Post & $22.1(20.8 / 23.5)$ & & & & \\
\hline \multirow{4}{*}{$\begin{array}{l}\text { Handgrip } \\
\text { Strength (kg) }\end{array}$} & \multirow{2}{*}{ Control } & Pre & $13.4(11.2 / 15.9)$ & \multirow{2}{*}{$0.2(-0.5 / 1.1)$} & \multirow{4}{*}{-2.514} & \multirow{4}{*}{$0.012^{*}$} & \multirow{4}{*}{0.25} \\
\hline & & Post & $13.0(12.1 / 15.5)$ & & & & \\
\hline & \multirow{2}{*}{ Experiment } & Pre & $12.7(10.3 / 15.4)$ & \multirow{2}{*}{$0.9(0.1 / 1.8)$} & & & \\
\hline & & Post & $14.3(12.1 / 16.1)$ & & & & \\
\hline \multirow{4}{*}{ Flexibility (cm) } & \multirow{2}{*}{ Control } & Pre & $11.0(6.0 / 15.0)$ & \multirow{2}{*}{$0.0(-1.0 / 1.0)$} & \multirow{4}{*}{-1.612} & \multirow{4}{*}{0.107} & \multirow{4}{*}{0.16} \\
\hline & & Post & $10.0(4.0 / 15.0)$ & & & & \\
\hline & \multirow{2}{*}{ Experiment } & Pre & $9.0(7.0 / 14.3)$ & \multirow{2}{*}{$1.0(-1.0 / 2.0)$} & & & \\
\hline & & Post & $10.0(6.0 / 14.3)$ & & & & \\
\hline
\end{tabular}

FC: Fall Count; ES: Effect Size (r) for Mann-Whitney U Test; Descriptive statistics are demonstrated as Median (25 / 75 percentiles). *p $<0.05$

As Table 2 shows hand-grip strength of active group were statistically higher than control one $(p=0.012)$, the mean values of balance, agility and elasticity did not reveal a significant difference between the groups $(\mathrm{p}=0.653, \mathrm{p}=0.706$, $\mathrm{p}=0.107$, respectively). According to this result, it can be said that 6-week resistance exercises applied with elastic resistance bands significantly increased hand-grip strength but not statistically significant effect on balance, agility and flexibility abilities.

\section{Discussion}

The aim of the study was to investigate the effects of 6-week resistance exercises with elastic resistance bands on balance, agility, hand-grip strength and flexibility in children aged 8-9. The main finding of the study is that resistance band exercises improved hand-grip strength $(\mathrm{p}=0.012)$ but did not affect flexibility and agility performance $(\mathrm{p}=0.706)$. It is known that hand-grip strength is a method that demonstrates the overall level of muscular fitness (Ortega, et al., 2008; Norman, et al., 2011; Newman, et al., 1984). Therefore, it can be assumed that 6-week elastic resistance band exercises applied to children in 8-9 age group increase general muscular fitness level of children. As it believed increase numerous factors, including increase in lean muscle mass, muscle hypertrophy, increase in muscle cross-sectional area, motor-unit coordination, central nervous system activation, and psychological drive may contribute to increases in hand 
grip strength (Sartorio et al., 2002; Guy and Michelli, 2001). However, strength enhancement in children is explained by neuromuscular activation and coordination increase rather than by muscular hypertrophy (Guy and Michelli, 2001).

The results showed 6-week elastic resistance band exercises do not have significant difference between control and experimental group in balance, flexibility and agility skills. It is reported resistance exercises 3 times a week for 14 weeks improve flexibility in pre-puberty boys (age: $8.2 \pm 1.3$ years) (Weltman et al., 1986) and 6-weeks (4 days per week) elastic resistances develop flexibility and balance of adults (age: $21.1 \pm 0.7$ years) (Selçuk, 2013). The results obtained from our study are different from Selçuk (2013) and Weltman et al. (1986) in terms of features such as flexibility and agility, so it may be due to the lack of homogeneity in terms of body mass and height characteristics of the participants in this study. As it is known exercises including muscular strength and power such as agility and sprint are influenced by features such as body size, height and weight. In subsequent studies, especially the normalization of body weight, in terms of reliability of results, can be very useful in explaining conflicting results (Karavelioglu, Harmanci, and Caliskan, 2017; Sartorio, 2002)

On the other hand, Docherty et al (1987) found that 12-year-old boys did not benefit from strength training following their competitive season. The different results obtained from the literature may be caused by differences in the age, gender, and physical activity levels of participants. Another reason for different results from these studies may be due to elements of training program (frequency, volume, intensity, type of resistance equipment, etc.) applied to the participants.

As a result of literature review, there was no study on the effect of elastic resistance band exercises on motor performance of 8-9 years old children. On the other hand, Joy et al. (2016) reported that elastic resistance band training, which is added once a week to resistance training for 14 national men's basketball team players improves muscular performance and Faigenbaum et al. (1993) reported that 8 weeks resistance exercises by children (10.8 years old) improved strength and enhanced body composition of them.

As there is no evidence of resistance elastic band exercises effect on agility of children, the results of agility obtained from this research remains open to debate.

\section{Conclusion and Recommendations}

By using resistance exercises for children, we give them opportunity to be physically active and can be avoided the potential harmful effects of dragging into a sedentary lifestyle. It is stated that regular participation in resistance exercises of children (9-18 years) affects the physical activity situation in adulthood and that these exercises positively affect general public health (Telama et al., 2005). Therefore, 6 weeks exercises along with elastic resistance bands can be added to school activity programs as an economical, fun and reliable method.

\section{Acknowledgements}

I would like to thank Prof. Dr. Bahtiyar Özçaldıran for encouraging me to do this study and Esay Demir, Büşra Görgülü, Nurbahar Özkan, Mustafa Aydemir, Yasin Küçükkırmızı, Dilan Aydın, Ayşe Ateş and Ahmet Akbal for their support in the process of collecting data.

\section{Conflict of Interests}

The authors declared no conflict of interests regarding the publication of this manuscript.

\section{References}

Behm, D. G., Faigenbaum, A. D., Falk, B., \& Klentrou, P. (2008). Canadian Society for Exercise Physiology position paper: resistance training in children and adolescents. Applied physiology, nutrition, and metabolism, 33(3), 547-561. https://doi.org/10.1139/H08-020

Behringer, M., Heede, A. V., Matthews, M., \& Mester, J. (2011). Effects of strength training on motor performance skills in children and adolescents: a meta-analysis. Pediatric Exercise Science, 23(2), 186-206. https://doi.org/10.1123/pes.23.2.186

Caine, D., DiFiori, J., \& Maffulli, N. (2006). Physeal injuries in children's and youth sports: reasons for concern? British journal of sports medicine, 40(9), 749-760. https://doi.org/10.1136/bjsm.2005.017822

Canl, U. (2017). The effect of strength trainings by using thera band on the motor skills and shooting performance of basketball players. International Journal of Social Sciences and Education Research, 3(3), 857-869. https://doi.org/10.24289/ijsser.310970

Connolly, S. A., Connolly, L. P., \& Jaramillo, D. (2001). Imaging of sports injuries in children and adolescents. Radiologic clinics of North America, 39(4), 773-790. https://doi.org/10.1016/S0033-8389(05)70310-9

DiFiori, J. P., Caine, D. J., \& Malina, R. M. (2006). Wrist pain, distal radial physeal injury, and ulnar variance in the 
young gymnast. The American journal of sports medicine, 34(5), 840-849. https://doi.org/10.1177/0363546505284848

Docherty, D. (1987). The effects of variable speed resistance training on strength development in prepubertal boys. Journal of Human Movement Studies, 13, 337-382.

Faigenbaum, A. D. (2007). State of the Art Reviews: Resistance Training for Children and Adolescents: Are There Health Outcomes? American Journal of Lifestyle Medicine, 1(3), 190-200. https://doi.org/10.1177/1559827606296814

Faigenbaum, A. D., \& Myer, G. D. (2010). Pediatric resistance training: benefits, concerns, and program design considerations. Current sports medicine reports, 9(3), 161-168. https://doi.org/10.1249/JSR.0b013e3181de1214

Faigenbaum, A. D., \& Myer, G. D. (2010). Resistance training among young athletes: safety, efficacy and injury prevention effects. British Journal of Sports Medicine. 44(1), 56-63. https://doi.org/10.1136/bjsm.2009.068098

Faigenbaum, A. D., Kraemer, W. J., Blimkie, C. J., Jeffreys, I., Micheli, L. J., Nitka, M., \& Rowland, T. W. (2009). Youth resistance training: updated position statement paper from the national strength and conditioning association. The Journal of Strength \& Conditioning Research, 23, S60-S79. https://doi.org/10.1519/JSC.0b013e31819df407

Faigenbaum, A. D., Zaichkowsky, L. D., Westcott, W. L., Micheli, L. J., \& Fehlandt, A. F. (1993). The effects of a twice-a-week strength training program on children. Pediatric Exercise Science, 5(4), 339-346. https://doi.org/10.1123/pes.5.4.339

Falk, B., \& Eliakim, A. (2003). Resistance training, skeletal muscle and growth. Pediatric endocrinology reviews: PER, l(2), 120-127.

Guy, J. A., \& Micheli, L. J. (2001). Strength training for children and adolescents. JAAOS-Journal of the American Academy of Orthopaedic Surgeons, 9(1), 29-36. https://doi.org/10.5435/00124635-200101000-00004

Joy, J. M., Lowery, R. P., Oliveira de Souza, E., \& Wilson, J. M. (2016). Elastic bands as a component of periodized resistance training. Journal of strength and conditioning research, 30(8), 2100-2106. https://doi.org/10.1519/JSC.0b013e3182986bef

Karavelioglu, M. B., Harmanci, H., \& Caliskan, G. (2017). Gender differences in hand grip strength of the child athletes by using absolute, ratio and allometric scaling methods. Biomedical Research, 28(4).

Lesinski, M., Prieske, O., \& Granacher, U. (2016). Effects and dose-response relationships of resistance training on physical performance in youth athletes: a systematic review and meta-analysis. Br J Sports Med, bjsports-2015. https://doi.org/10.1136/bjsports-2015-095497

Malina, R. M. (2006). Weight training in youth-growth, maturation, and safety: an evidence-based review. Clinical Journal of Sport Medicine, 16(6), 478-487. https://doi.org/10.1097/01.jsm.0000248843.31874.be

Myer, G. D., \& Wall, E. J. (2006). Resistance training in the young athlete. Operative techniques in sports Medicine, 14(3), 218-230. https://doi.org/10.1053/j.otsm.2006.04.004

Newman, D. G., Pearn, J., Barnes, A., Young, C. M., Kehoe, M., \& Newman, J. (1984). Norms for hand grip strength. Archives of disease in childhood, 59(5), 453-459. https://doi.org/10.1136/adc.59.5.453

Norman, K., Stobäus, N., Gonzalez, M. C., Schulzke, J. D., \& Pirlich, M. (2011). Handgrip strength: outcome predictor and marker of nutritional status. Clinical nutrition, 30(2), 135-142.21. Osbahr, D. C., Cannon, D. L., \& Speer, K. P. (2002). Retroversion of the humerus in the throwing shoulder of college baseball pitchers. The American journal of sports medicine, 30(3), 347-353.

Ortega, F. B., Ruiz, J. R., Castillo, M. J., \& Sjöström, M. (2008). Physical fitness in childhood and adolescence: a powerful marker of health. International journal of obesity, 32(1), 1-11. https://doi.org/10.1038/sj.ijo.0803774

Özer, K. (2000). Motor Development in Children, Kazancı Matbaacılık, Istanbul.

Reagan, K. M., Meister, K., Horodyski, M. B., Werner, D. W., Carruthers, C., \& Wilk, K. (2002). Humeral retroversion and its relationship to glenohumeral rotation in the shoulder of college baseball players. The American journal of sports medicine, 30(3), 354-360. https://doi.org/10.1177/03635465020300030901

Saha, S. (2014). Education Students and its Relationship with Body Composition and Somatotype. Middle-East Journal of Scientific Research, 21(3), 502-508.

Şahin, G., Aslan, M., \& Demir, E. (2016). Short-term effect of back squat with an elastic band on the squat and vertical jump performance in trained children. Journal of Physical Education and Sport, 16(1), 97. 
Sartorio, A., Lafortuna, C. L., Pogliaghi, S., \& Trecate, L. (2002). The impact of gender, body dimension and body composition on hand-grip strength in healthy children. Journal of endocrinological investigation, 25(5), 431-435. https://doi.org/10.1007/BF03344033

Selçuk, H. (2013). The effects of 12-weeks thera-band training on swimming performance with some motoric features at 11-13 age group swimmers. Doctoral thesis, Selçuk University, Health Sciences Institute, Turkey.

Telama, R., Yang, X., Viikari, J., Välimäki, I., Wanne, O., \& Raitakari, O. (2005). Physical activity from childhood to adulthood: a 21-year tracking study. American journal of preventive medicine, 28(3), 267-273. https://doi.org/10.1016/j.amepre.2004.12.003

Weltman, A. R. T. H. U. R., Janney, C. A. R. O. L., Rians, C. B., Strand, K., Berg, B., Tippitt, S., ... \& Katch, F. I. (1986). The effects of hydraulic resistance strength training in pre-pubertal males. Medicine and Science in Sports and Exercise, 18(6), 629-638. https://doi.org/10.1249/00005768-198612000-00005

Willems, T. M., Witvrouw, E., Delbaere, K., et al. Intrinsic risk factors for inversion ankle sprains in females: a prospective study. Scand J Med Set Sports 2005 Oct; 15(5), 336-345. https://doi.org/10.1111/j.1600-0838.2004.00428.x

Yolcu, S. Ö. (2010). Effects of training with machines versus resistive bands on muscular strength of pre-pubertal children. Master thesis, Ege University, Health Sciences Institute, Turkey.

\section{Copyrights}

Copyright for this article is retained by the author(s), with first publication rights granted to the journal.

This is an open-access article distributed under the terms and conditions of the Creative Commons Attribution license which permits unrestricted use, distribution, and reproduction in any medium, provided the original work is properly cited. 